$15^{\text {th }}$ International Conference on

AEROSPACE SCIENCES \& AVIATION TECHNOLOGY,

ASAT - 15 - May 28 - 30, 2013, Email: asat@mtc.edu.eg,

Military Technical College, Kobry Elkobbah, Cairo, Egypt,

Tel: +(202) 24025292 -24036138, Fax: +(202) 22621908

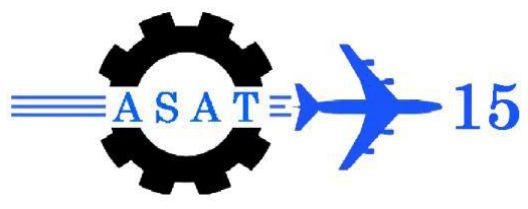

\title{
Study of the Aerodynamic Characteristics of an Agricultural Spraying UAV*
}

\{M. A. Mohamed, A. A. Mohamed, H. A. Hassan, M. S. Musa, A. A. Abdalslam, H. G. Alkaleg $\}^{\dagger}$, Tariq H. Elsonni ${ }^{\ddagger}$ Emad A. Musa ${ }^{\S}$

\begin{abstract}
The aim of this paper is to determine and study the aerodynamics characteristics of an Agricultural Spraying Unmanned Air Vehicle (ASUAV) that designed in the Faculty of Engineering-Omdurman Islamic University. Since flight testing can be expensive and dangerous, other methods are required to simulate flight test conditions for low subsonic vehicle system. In this research, Computational Fluids Dynamics (CFD) was used to simulate the flight test and determine the aerodynamic characteristics such as lift and drag coefficients at various angles of attack. The quality of flow pattern around the ASUAV was clearly observed. Generally, the current approach shows that the proposed configuration has suitable aerodynamic characteristics. The promising results of this study opened the door for developing and manufacturing the ASUAV which have been successfully flight in June 2012 .
\end{abstract}

Keywords: Agriculture, spraying UAV, CFD, aerodynamics, flight test.

\section{Nomenclature}

AUAS Agricultural Spraying Unmanned Air Vehicle

CFD Computational Fluid Dynamics

\section{Introduction}

Application of crop production and protection materials is crucial component in the high productivity of Sudan agricultural sector. Agricultural application of fertilizers and chemicals is frequently needed at specific times and locations for accurate site-specific management of crop pests. These applications are typically made through the use of ground sprayers, chemigation, or aerial application equipment (Piloted agricultural aircraft). While these methods are well suited to treat large, unobstructed, continuous acreage cropping systems; they may become inefficient or cumbersome when applications must be made over small or obstructed plot production systems.

An Unmanned Aerial Vehicle (UAV), which can be remotely controlled or fly autonomously based on pre-programmed flight plans, more maneuverable, cheaper to operate, and require less capital costs, may serve to address this need.

\footnotetext{
Student Innovation.

$\dagger \quad$ Graduates engineers (Bachelor of Science), Dept. of Mechanical Engineering, Omdurman Islamic University, Khartoum, Sudan; shk2858@yahoo.com .

$\$$ Assistant Professor of Aeronautical Engineering, Khartoum Academy for Aviation and Technology, Khartoum, Sudan; lnt273@yahoo.com.

$\S$ Assistant professor, Department of Aeronautical Engineering, Karary University, Khartoum, Sudan.
} 
In Sudan, several researches have been extended to address several issues in developing the UAVs in the field of agricultural applications. With these considerations in mind, the present work believes that universities and research centers represent one of the most important fields that still need continuous work and development in incorporating UAVs to the application of the agricultural sector and relating the design challenges involved. As a consequence, this study was devoted towards this new direction. As part of this effort in Omdurman Islamic university, a team of six undergraduate students undertaking a final year Design Project to reflect on both the learning process and the outcomes of the ASUAV project. This paper represents a preliminary overview of the students' findings and provides a basis from which to conduct further, more detailed, investigations at later stages.

\section{Numerical Approach}

\subsection{Flow Solver}

The present computations considered unstructured grids, and they have been constructed using FLUENT-software, the well-known commercial code. This CFD code use numerical method to solve and analyze problem that involve fluid flow[1]. It uses finite difference method to describe the unknown flow problem by means of a domain discretized into a series of grid points.

\subsection{Grid Generation}

The first step used in estimating the aerodynamic characteristics of ASUAV is to design a CAD model as shown in figure 1. This file is exported as a step file to GAMBIT. The flow domain about the geometry is discretized using unstructured grids. To assure faster convergence and good solution, the mesh quality in GAMBIT must be taken in account, besides using the size function to solve difficulties in meshing process.

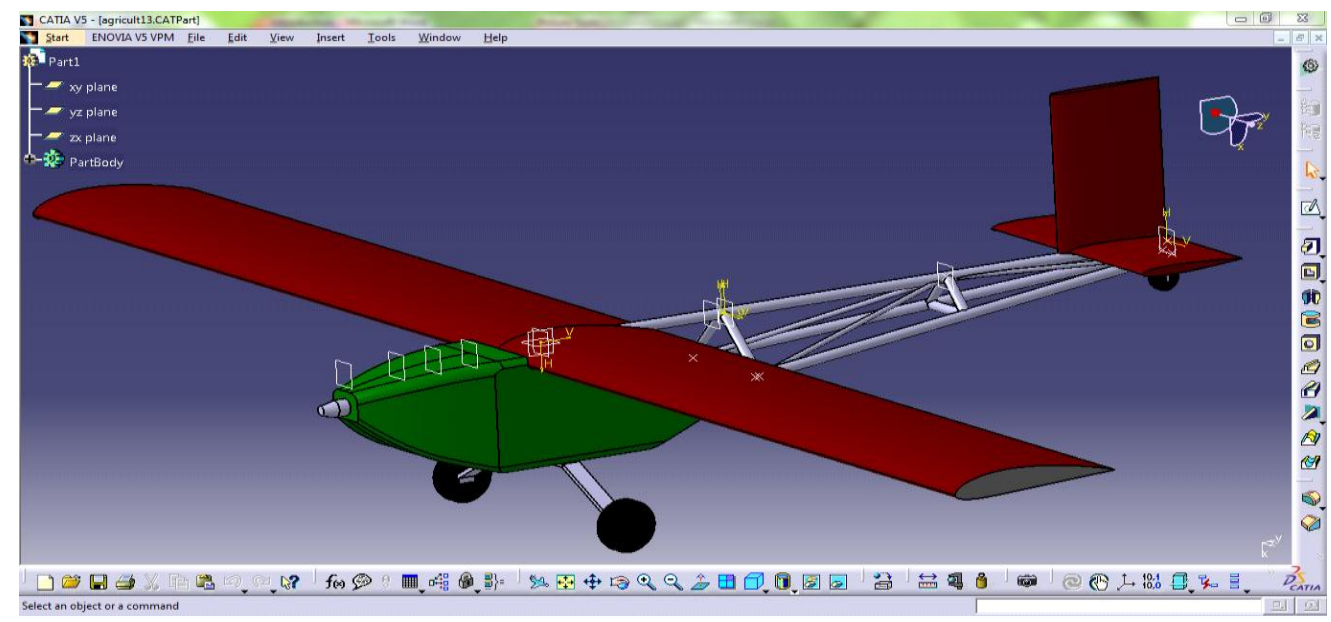

Fig. 1 CATIA model of the ASUAV

\subsection{Meshing Process}

The approximate fixed curvature and meshed type of size functions are defined to control the size of element edges. Sample of the computational mesh for the full configuration is presented in figure 2. A tri-mesh-pave is used for meshing the faces of irregular shapes; while a tetrahedral meshing is applied on the flow volume represents the brick that surrounds the ASUAV model. The flow volume size was $(12.5,10,10) \mathrm{m}$. 


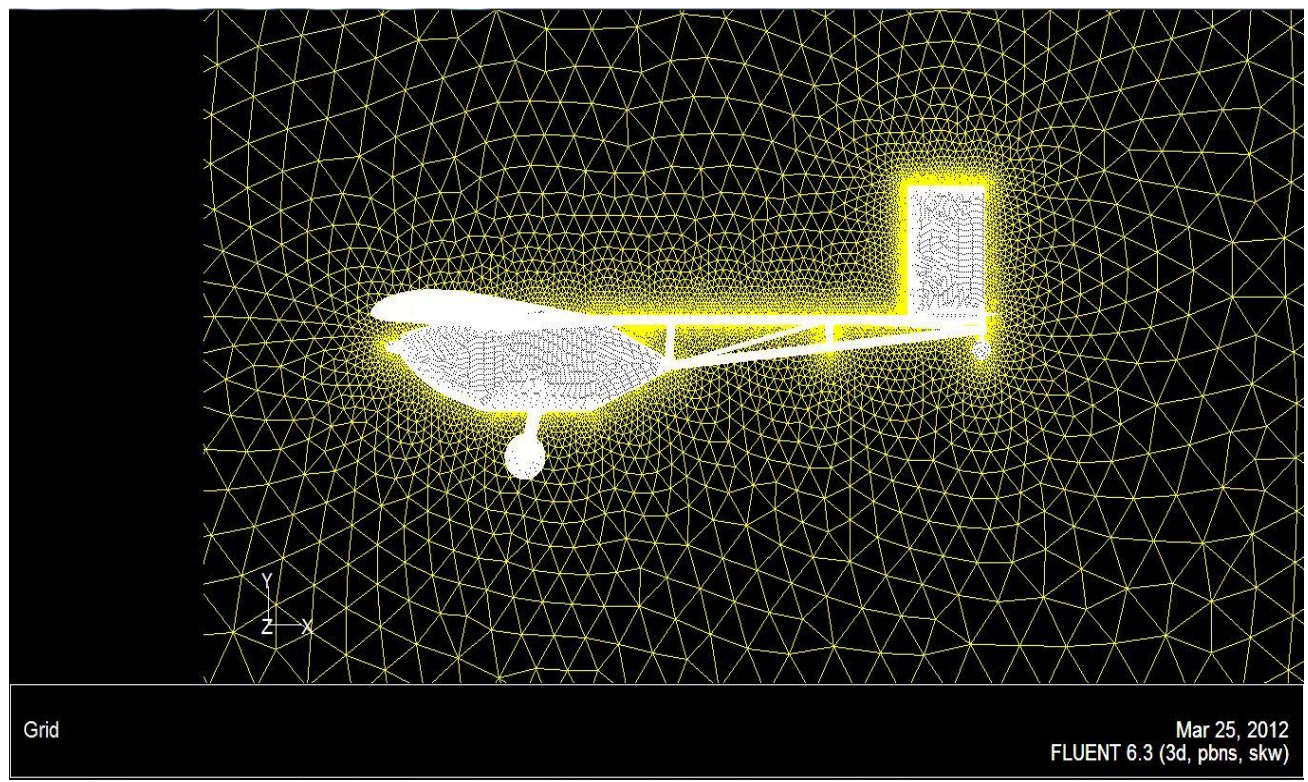

Fig. 2 Mesh of ASUAV full configuration

\subsection{Viscous Model}

To estimate an actual flow around the targeted model, two different viscous models are chosen. These models are K- $\varepsilon$ standard; which is used for the maximum speed $\left(\mathrm{V}_{\mathrm{m}}=\right.$ $51.816 \mathrm{~m} / \mathrm{s})$ and $\mathrm{K}-\omega$ standard which is used for the cruise speed $\left(\mathrm{V}_{\mathrm{c}}=36 \mathrm{~m} / \mathrm{s}\right)$.

\subsection{Post Processor for Aerodynamic Forces}

The post processor, by means and useful tools allow the evaluation of aerodynamics forces and the observation of the flow field variables. From the evaluation of forces over the ASUAV for several flight conditions, i.e., varying the angle-of-attack, the relevant aerodynamic coefficients could be extracted. With such data, one can analyze details of ASUAV flight conditions and possible stability range. The aerodynamic coefficients evaluated in present work are only valid for different angles of attack, since steady flow conditions are assumed, the calculations beyond stall would be incorrect.

\subsection{Parametric Study}

This study explores the main aerodynamic characteristics of the ASUAV and includes two major objectives:

1- To verify the velocity influence over the aerodynamic coefficients.

2- To verify the overall aerodynamic behavior at different angle of attack, and for different viscous model.

Velocity variation studies allow the verification that the aerodynamic coefficients do not change with flow speed, but when used different viscous models for same speed the aerodynamic coefficients were change, also aerodynamic coefficient change with variation of angle of attack. 


\section{Aerodynamics Results}

\subsection{Lift Coefficient vs. Angle of Attack $\left(C_{L}\right.$ vs. $\left.\alpha\right)$}

In figure $3, \mathrm{C}_{\mathrm{L}}$ grows linearly with angle of attack, but when $\alpha$ becomes larger the flow tends to separate (stall) from the top surface of ASUAV especially in wing and this creating large wakes (vortex).

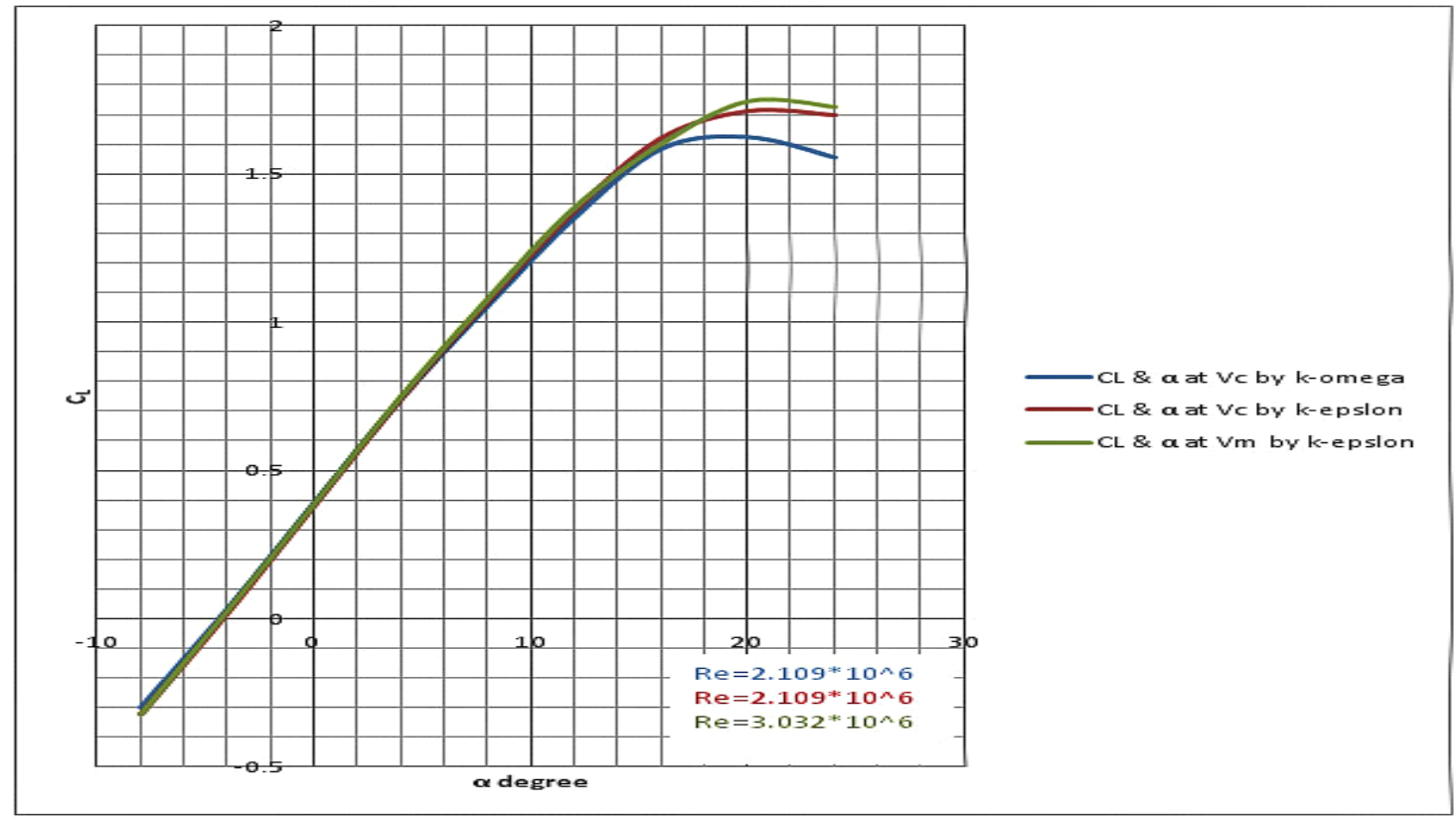

Fig. 3 Lift Coefficient vs. Angle of Attack $\left(C_{L}\right.$ vs. $\left.\alpha\right)$

\subsection{Drag Coefficient vs. Angle of Attack $\left(C_{D} \& \alpha\right)$}

The drag coefficient with angle of attack is parabolic curve, which indicates that drag increase with the angle of attack, see figure 4.

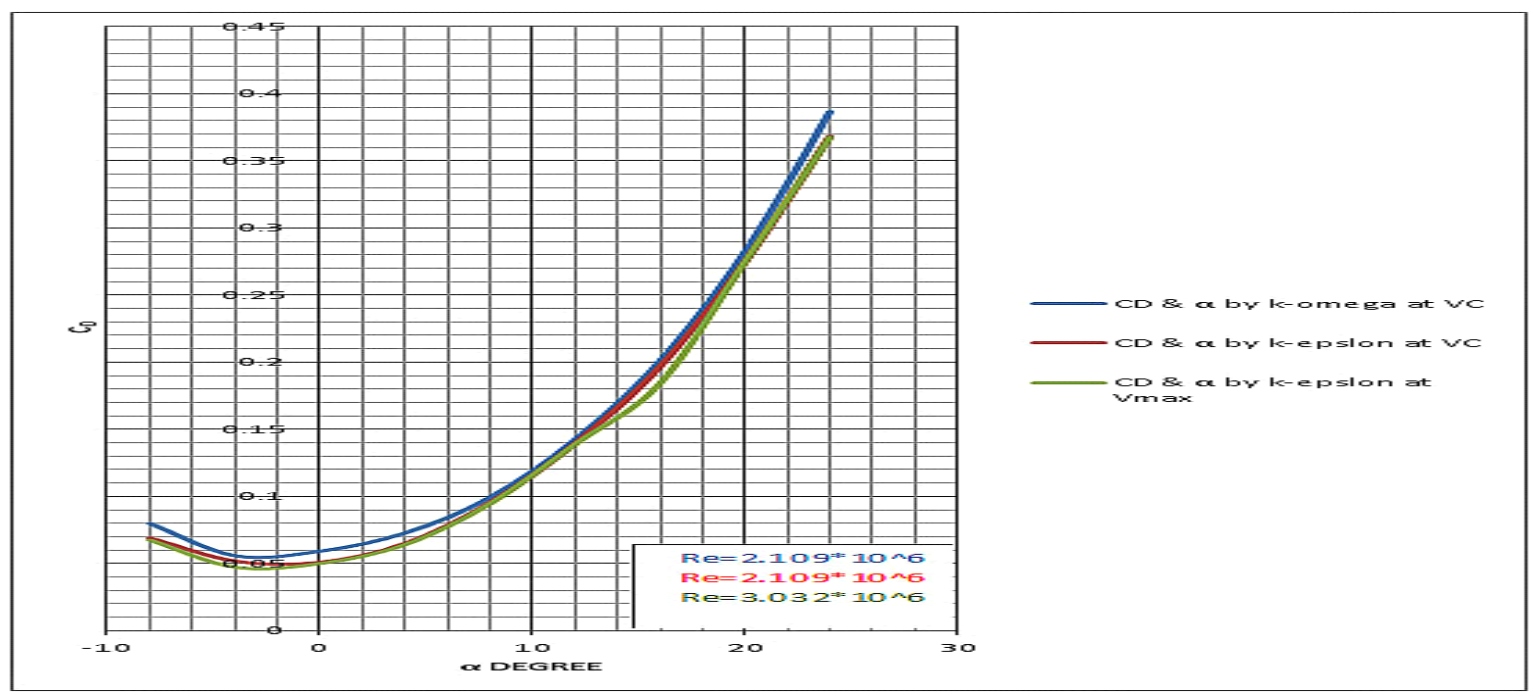

Fig. 4 Drag Coefficient vs. Angle of Attack ( $C_{D}$ vs. $\left.\alpha\right)$ 


\section{$3.3 \mathrm{C}_{\mathrm{L}} / \mathrm{C}_{\mathrm{D}}$ vs. $\alpha$}

The aerodynamic efficiency behavior, in terms of the lift-to-drag ratio, at different angles of attack can be seen in figure 5. This ratio is used to determine the optimum angle of attack that has maximum lift and minimum drag. As seen in figure 5, a considerable loss of efficiency can be observed as the angle of attack increases. $\left(\mathrm{C}_{\mathrm{L}} / \mathrm{C}_{\mathrm{D})}\right.$ values are quite reduced due to, most probably, the fairly large induced drag produced by the aircraft.

The drag polar determination based on the weight data which was generated during the sizing processes together with the basic geometric characteristics [2,3].

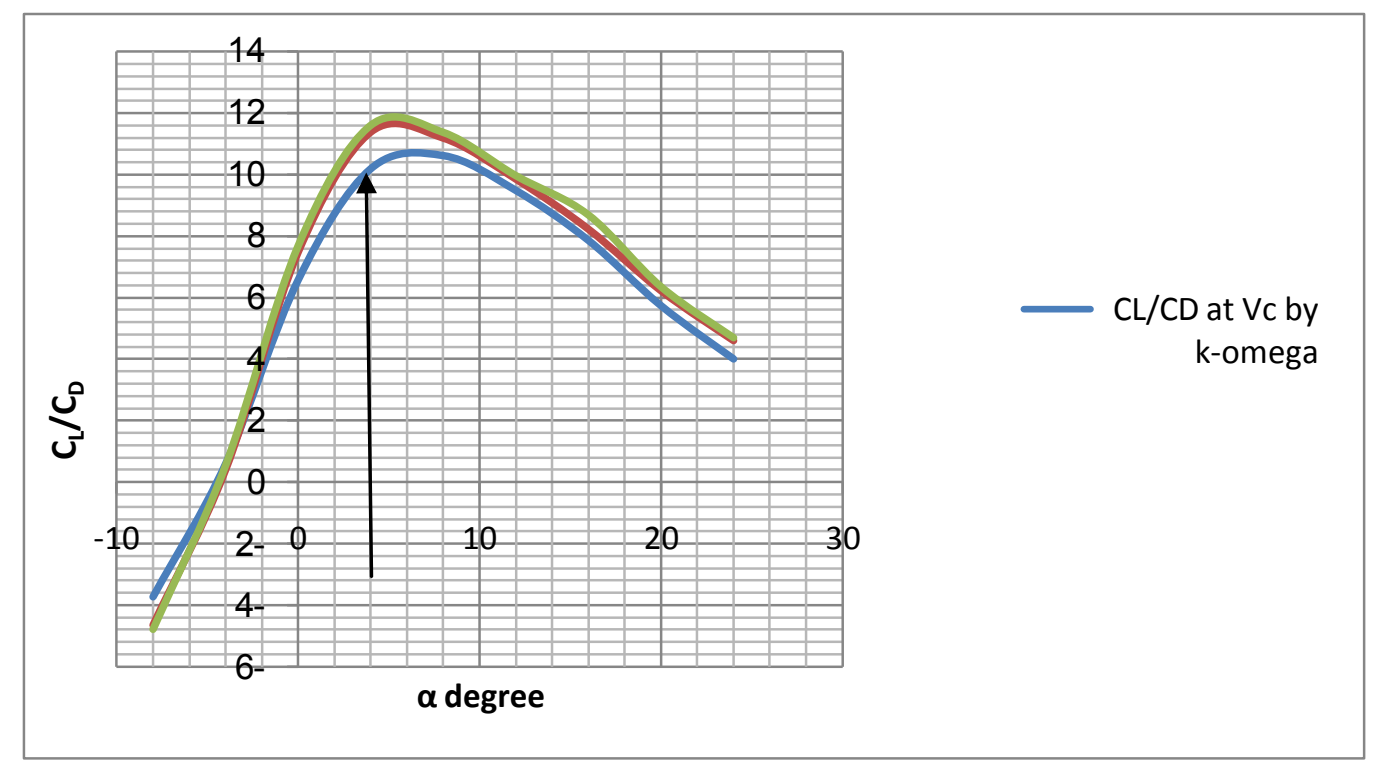

Fig. $5 C_{L} / C_{D}$ vs. $\alpha$

From the previous analysis the following results are presented:

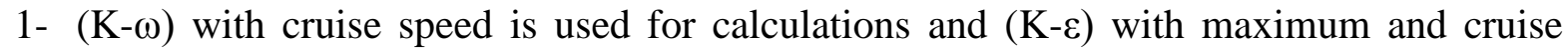
speeds for comparisons.

2- The zero lift angle of attack is $\left(\alpha_{0}=-4^{\circ}\right)$.

3- The suitable lift to drag ratio is $\left(C_{L} / C_{D}=10.314\right)$ with an angle of attack $\left(\alpha=4^{\circ}\right)$ which has lift coefficient $\left(C_{L}=0.823\right)$ and drag coefficient $\left(C_{D}=0.079\right)$.

4- The stall angle of attack is $\left(\alpha_{\text {stall }}=20^{\circ}\right)$ which has maximum lift coefficient $\left(\mathrm{C}_{\mathrm{Lmax}}\right.$ $=1.0624)$.

\subsection{The Pressure Distribution of the ASUAV}

The distribution of the static pressure on the upper and lower surfaces of the ASUAV is only estimated for the angle of attack $\left(\alpha=4^{\circ}\right)$, figure 6 . A higher static pressure was observed on the lower surfaces, this pressure is responsible of lifting the aircraft. The path lines of flow velocity magnitude distribution for stall angle of attack $\left(\alpha_{\text {stall }}=20^{\circ}\right)$ is depicted in figure 7 . 


\section{Performance}

Figure 8 shows the relationship between available power and the required power with flight velocity. The power available is $P_{A}=23.862 \mathrm{kw}$. Figure 8 shows that the power required decreases with increasing velocity until the power required reaches its minimum value at certain velocity, then the power required starts to increase with the increasing flight velocity. This figure indicates that the minimum power required is $P_{\min }=7.51 \mathrm{kw}$ and occurs at the velocity $V_{m p}=18.89 \mathrm{~m} / \mathrm{s}$. Also can be inferred from the shape the maximum velocity $V_{\max }=42.672 \mathrm{~m} / \mathrm{s}$, the optimum velocity $V_{\text {opt }}=25.91 \mathrm{~m} / \mathrm{s}$ and minimum velocity $V_{\min }=4.572 \mathrm{~m} / \mathrm{s}$ but this velocity is not used in the field of aviation because the stall velocity is the largest, $V_{\text {stall }}=18.89 \mathrm{~m} / \mathrm{s}$.

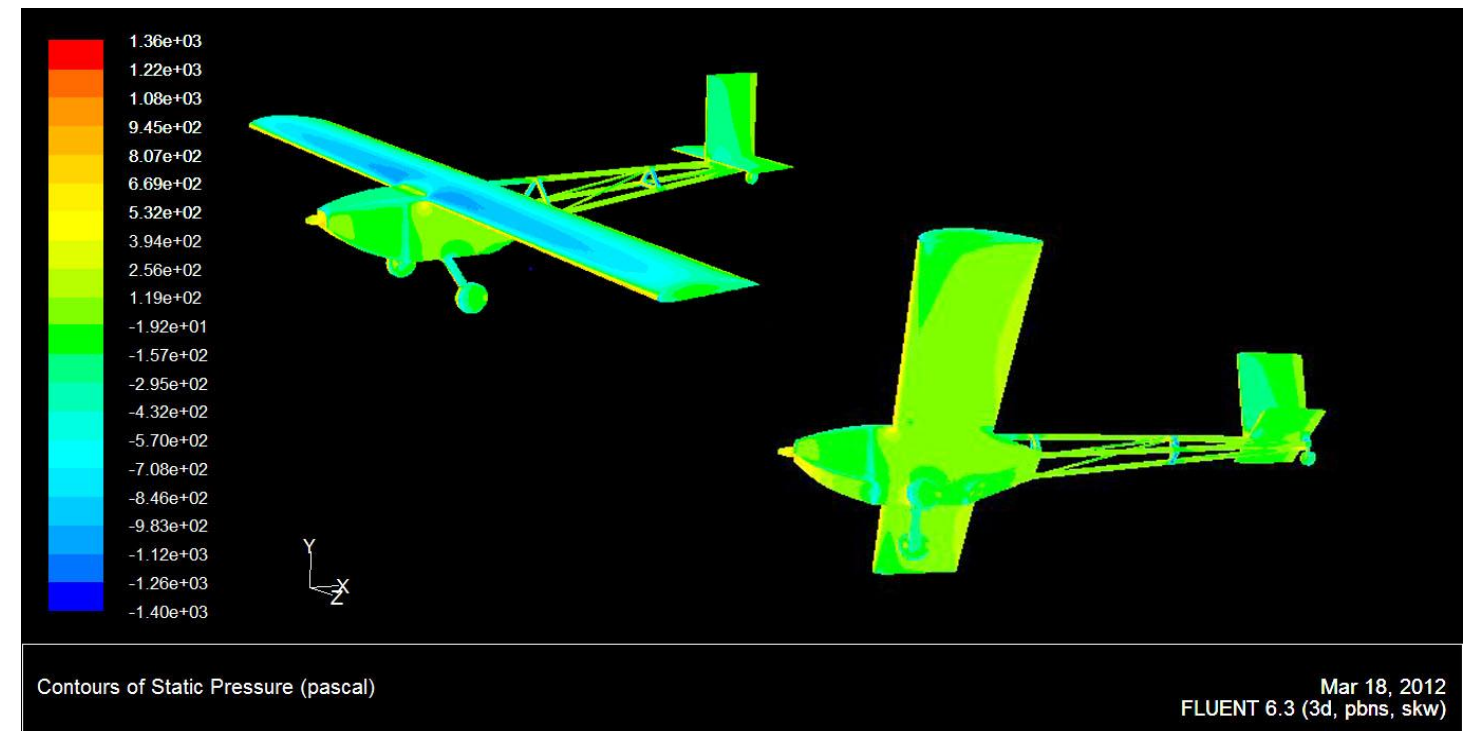

Fig. 6 The static pressure distribution on the upper and lower surfaces of the ASUAV for $\left(\alpha=4^{0}\right)$.

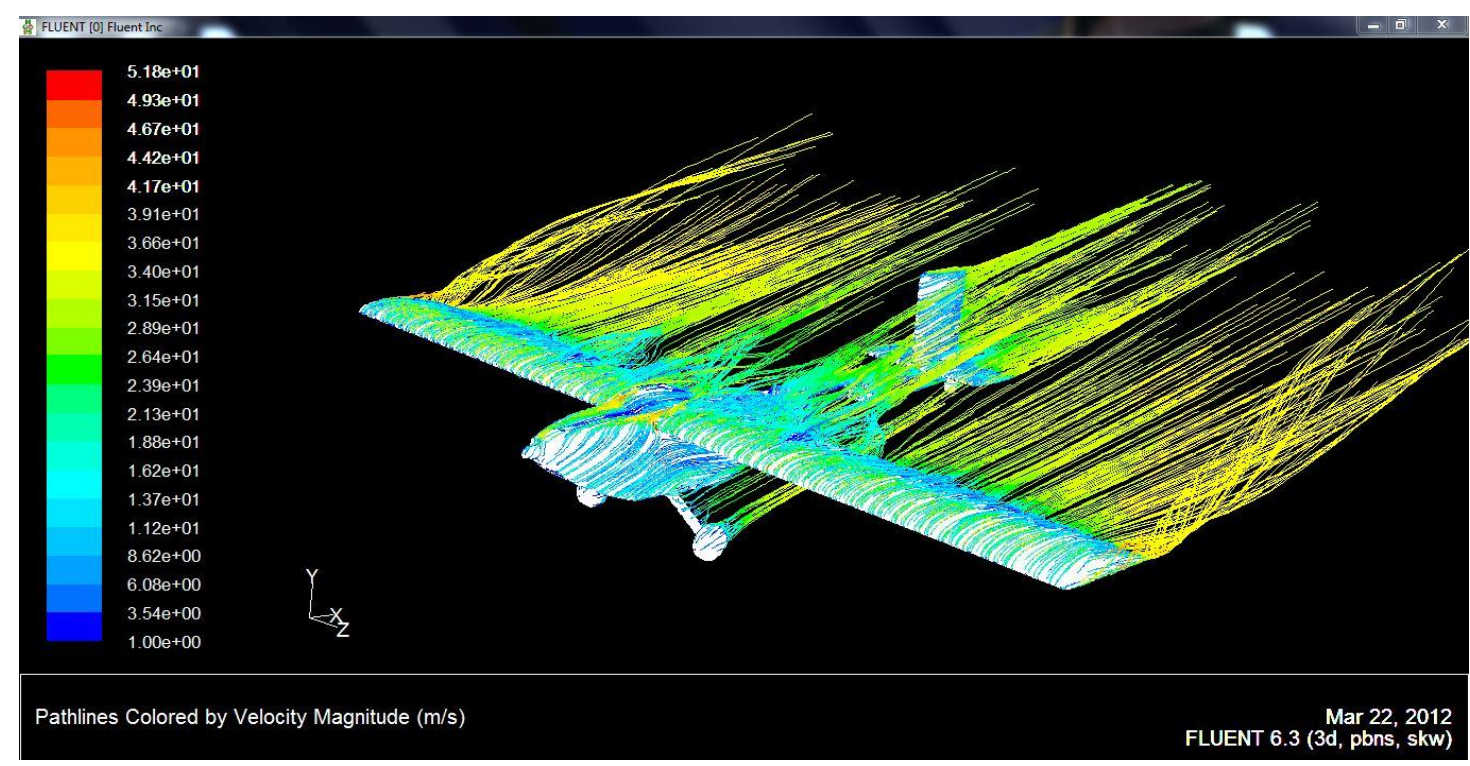

Fig. 7 The path lines of the flow velocity magnitude for $\left(\alpha=20^{\circ}\right)$. 


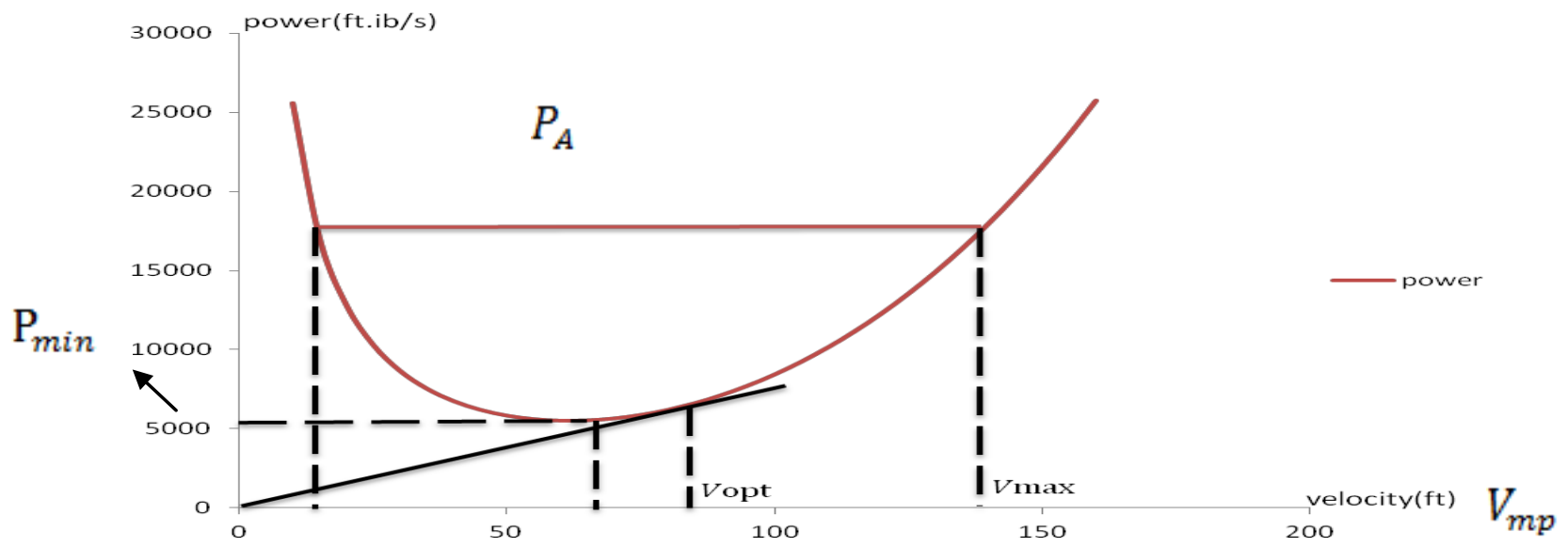

Fig. 8 Power available and power required against the velocity of steady flight

Figure 9 shows the relationship between radius of curvature and flight velocity of the agricultural aircraft. As shown in the figure the radius of curvature magnitude can be increased by increasing the velocity until the radius reach to its maximum value, after this intervention the ASUAV in this case lack of control that means stall may occur and the maximum radius of curvature is $R c_{\max }=27.74 \mathrm{~m}$.

Table 1 shows the important performance parameters determined for the ASUAV model.

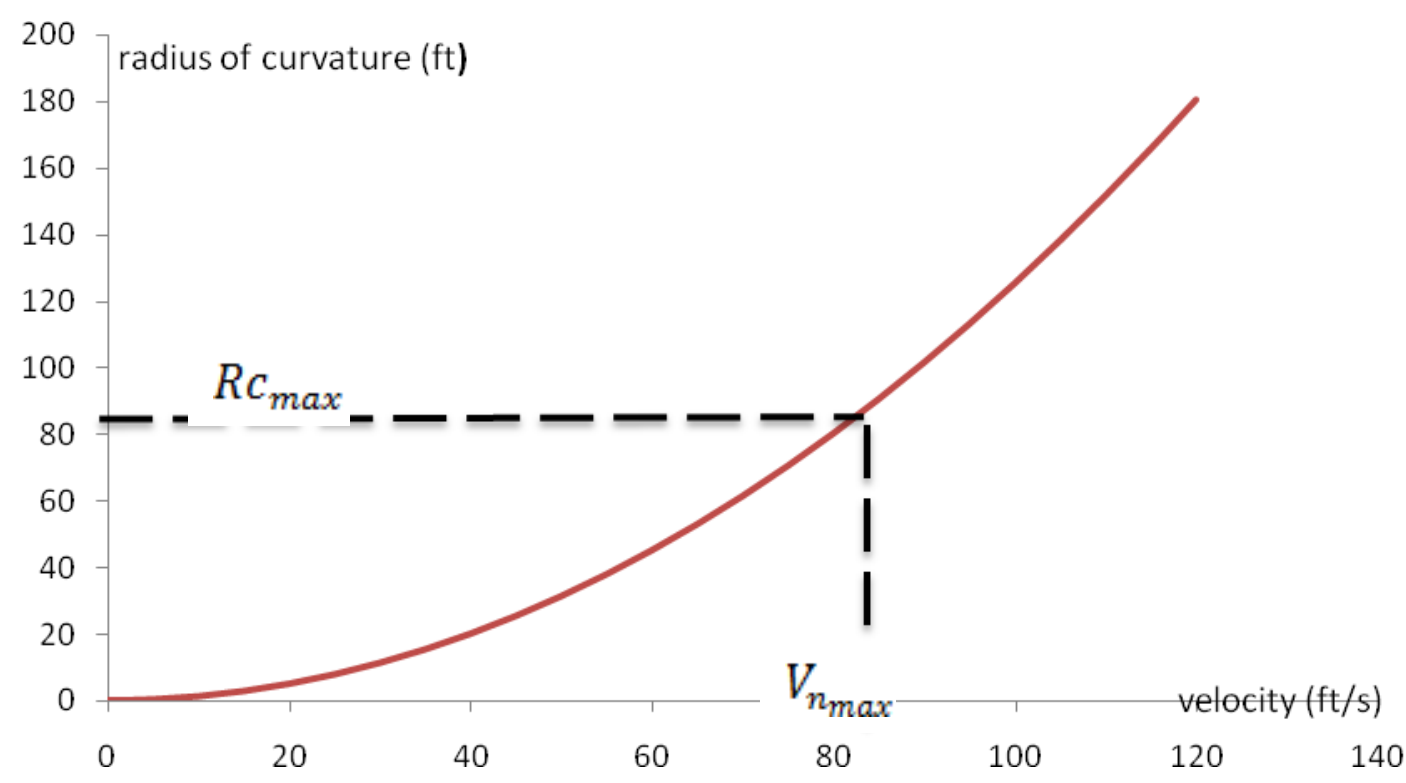

Fig. 9 Radius of curvature against the velocity for steady flight 
Table 1 Performance Parameters for the ASUAV Model

\begin{tabular}{|c|c|c|c|c|c|}
\hline Parameter & Value & Parameter & Value & Parameter & Value \\
\hline $\mathrm{D}_{\text {minm }}$ & $35.24 \mathrm{~kg}$ & $\gamma_{\max }$ & $15.3^{2}$ & $\varphi_{c \lim b}$ & $9.5^{\circ}$ \\
\hline $\mathbb{V}_{R}$ & $\begin{array}{c}24.39 \\
\mathrm{~m} / \mathrm{s}\end{array}$ & $t_{0}$ & $145 \mathrm{~s}$ & $\left(s_{2}\right)$ & $68.6 \mathrm{~m}$ \\
\hline$V_{C}$ & $\begin{array}{c}32.61 \\
\mathrm{~m} / \mathrm{s}\end{array}$ & ABSOLUTE $E_{\text {CIELNG }}$ & $\begin{array}{c}6.096 \\
\mathrm{~km}\end{array}$ & $\left(t_{2}\right)_{n 0}$ & $6.3 \mathrm{~s}$ \\
\hline$P_{A}$ & $\begin{array}{c}23.862 \\
\mathrm{kw}\end{array}$ & SERVIES & $5.486 \mathrm{~km}$ & $s_{T 0}$ & $224.05 \mathrm{~m}$ \\
\hline$P_{\text {smins }}$ & $7.51 \mathrm{kw}$ & CRUISE $_{\text {CEIUNG }}$ & $4.572 \mathrm{~km}$ & $t_{T 0}$ & $21.5 \mathrm{~s}$ \\
\hline$\nabla_{\mathrm{Xg}}$ & $18.9 \mathrm{~m} / \mathrm{s}$ & $n_{\max }$ & 1.8645 & $\left(s_{1}\right)_{m n}$ & $121.92 \mathrm{~m}$ \\
\hline$V_{\text {max }}$ & $12.2 \mathrm{~m} / \mathrm{s}$ & $V_{\text {maxax }}$ & $\begin{array}{c}25.908 \\
\mathrm{~m} / \mathrm{s}\end{array}$ & $\left(s_{2}\right)_{m n}$ & $19.812 \mathrm{~m}$ \\
\hline$V_{\text {opt }}$ & $\begin{array}{c}25.91 \\
\mathrm{~m} / \mathrm{s}\end{array}$ & $R c_{\text {max }}$ & $27.74 \mathrm{~m}$ & $\left(s_{a}\right)_{h n}$ & $53.04 \mathrm{~m}$ \\
\hline$V_{\text {ming }}$ & $\begin{array}{c}4.572 \\
\mathrm{~m} / \mathrm{s}\end{array}$ & $\mathrm{R}$ & $71420 \mathrm{ft}$ & $\left(t_{1}\right)_{n}$ & $9.5 \mathrm{~s}$ \\
\hline $\mathbb{V}_{\text {gtall }}$ & $18.9 \mathrm{~m} / \mathrm{s}$ & $\mathrm{c}$ & $\begin{array}{c}0.000042 \\
1 / \mathrm{s}\end{array}$ & $\left(t_{2}\right) \mathrm{ms}$ & $4.5 \mathrm{~s}$ \\
\hline$R o C_{\max }$ & $4.81 \mathrm{~m} / \mathrm{s}$ & $E$ & $1888 \mathrm{~s}$ & $s_{n n}$ & $194.772 \mathrm{~m}$ \\
\hline$V_{\text {RoG } \max }$ & $18.9 \mathrm{~m} / \mathrm{s}$ & $\left(s_{1}\right)_{10}$ & $155.45 \mathrm{~m}$ & $t_{\ln }$ & $13.5 \mathrm{~s}$ \\
\hline$V_{P_{\max }}$ & $30 \mathrm{~m} / \mathrm{s}$ & $\left(t_{1}\right)_{T \emptyset}$ & $15.2 \mathrm{~s}$ & & \\
\hline
\end{tabular}

\section{Longitudinal Static Stability}

The longitudinal static stability has been calculated using (AXIMER) program. This program is used to obtain to the best results by easy method. Most results obtained from aerodynamic analysis are used as inputs data for this program and its gives the main contribution of stability and the location of center of gravity and elevator deflection. The longitudinal static stability has been realized as seen in figure 10 .

The important stability parameters are collected in Table 2.

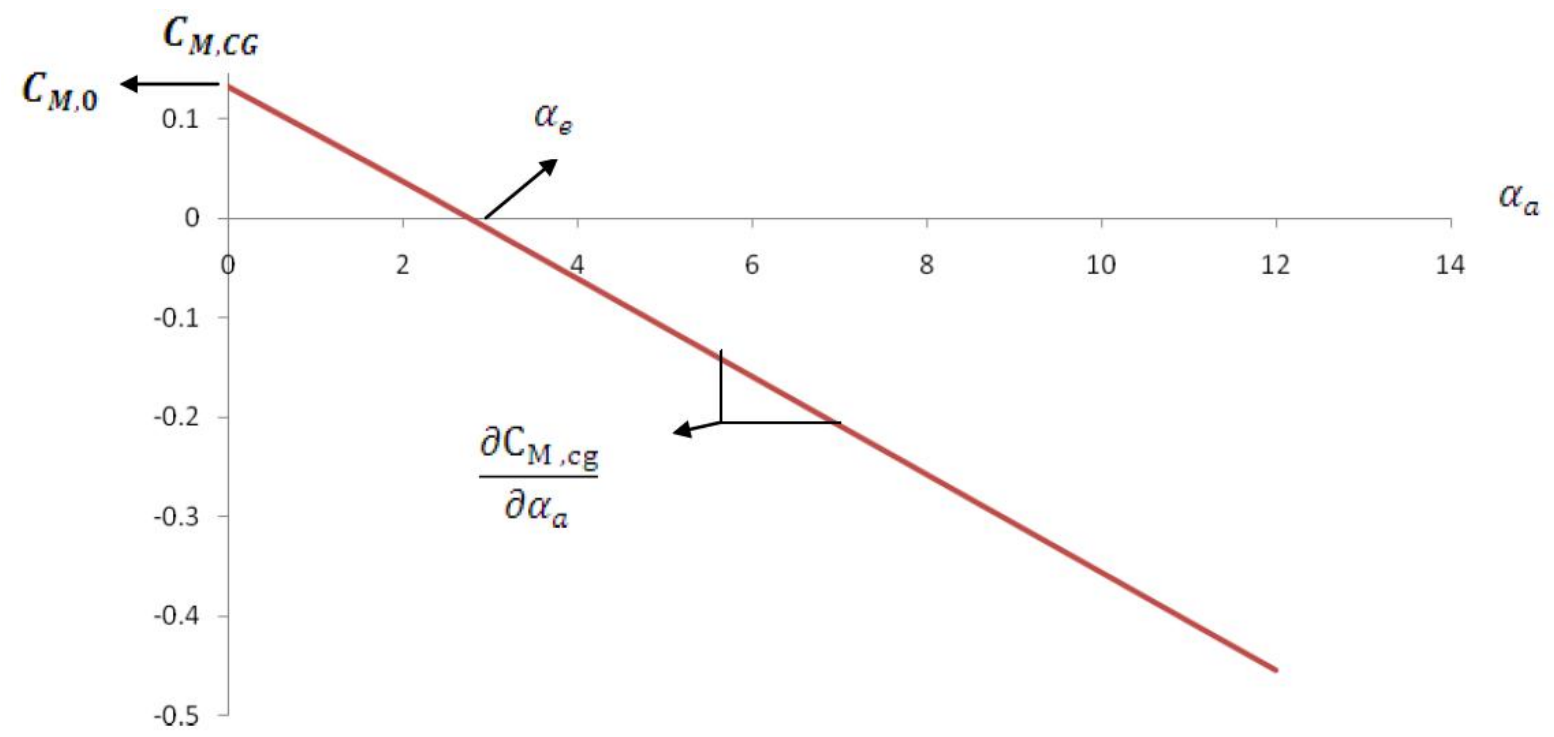

Fig. 10 The moment coefficient about center of gravity against angle of attack 
Table 2 Static Stability Parameters

\begin{tabular}{|c|c|}
\hline Parameter & Values \\
\hline$C_{M M_{0}}$ at $a_{W Y b}=0$ & 0.1324 \\
\hline$C_{\text {agg at } \alpha_{a x b}=12}$ & -0.442 \\
\hline$\sigma_{\theta}$ & $2.7^{\circ}$ \\
\hline$\frac{\partial \mathrm{C}_{\mathrm{MI}_{\alpha \mathrm{E}}}}{\partial \mathrm{c}_{\mathrm{a}}}$ & -0.047 \\
\hline$h_{n g}$ & 0.808 \\
\hline Static margin & 0.558 \\
\hline
\end{tabular}

\section{Manufacturing}

To simplify the manufacturing and reducing the cost, the ASUAV is scaled down by (1/4) scale factor.

\subsection{Wing and Tail Unit Manufacturing}

The main parts of the wing and tail unit (spars and ribs) are fabricated from plywood while the skins are made of foam with control surfaces made of balsa wood. Sticker is used to cover all skins. Figure 11 shows the ribs of the wing attached to the spar.

\subsection{Fuselage Manufacturing}

The front fuselage is fabricated from plywood while the rear one is made in the form of a truss type-fuselage made of aluminum rods as seen in figure 12 .

Fig. 11 The ribs attached to wing spar 


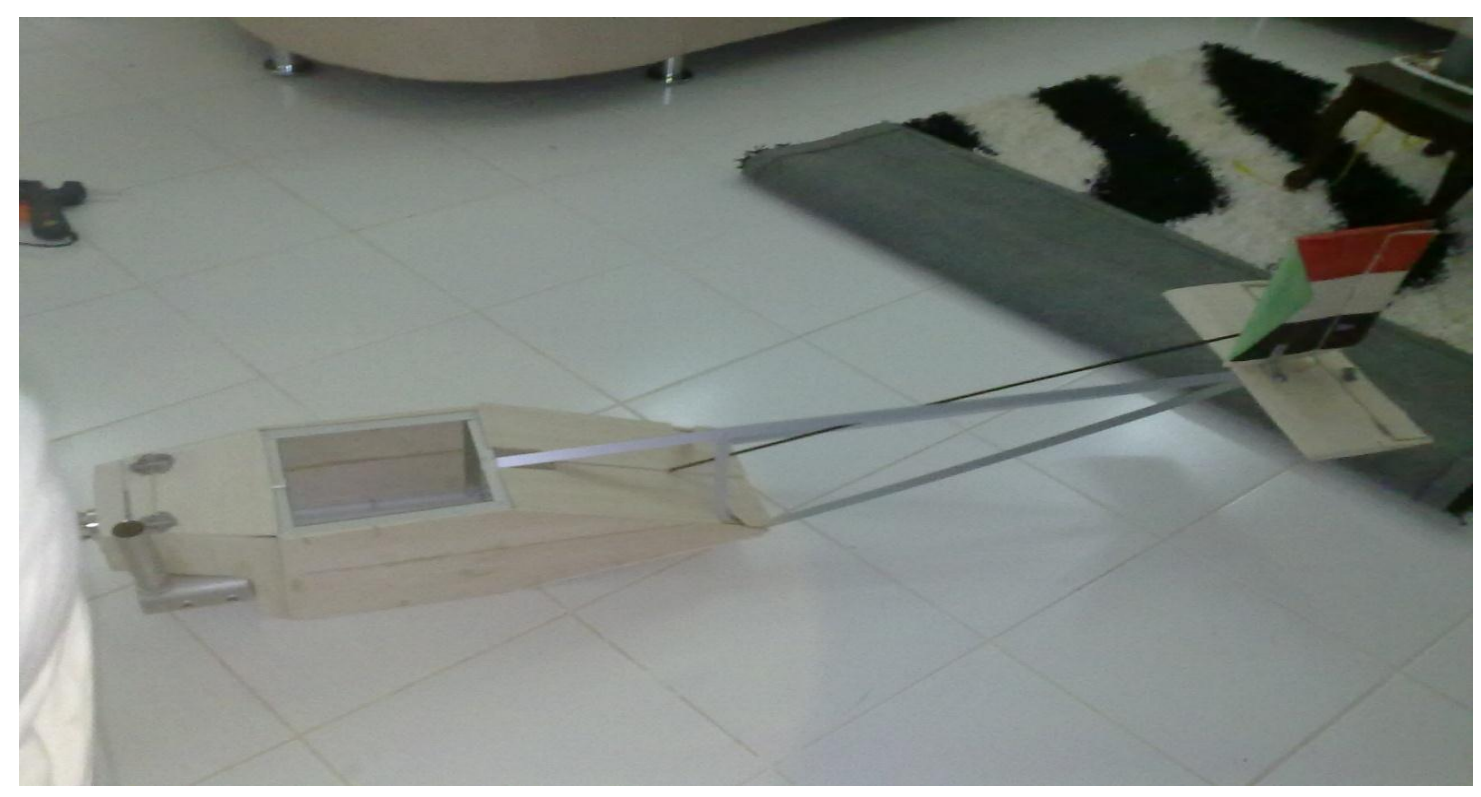

Fig. 12 The fuselage of theASUAV

\subsection{Landing gear Manufacturing}

The landing gear strut is made of aluminum, figure 13 .

The final scaled model of the ASUAV is depicted in figure 14 .
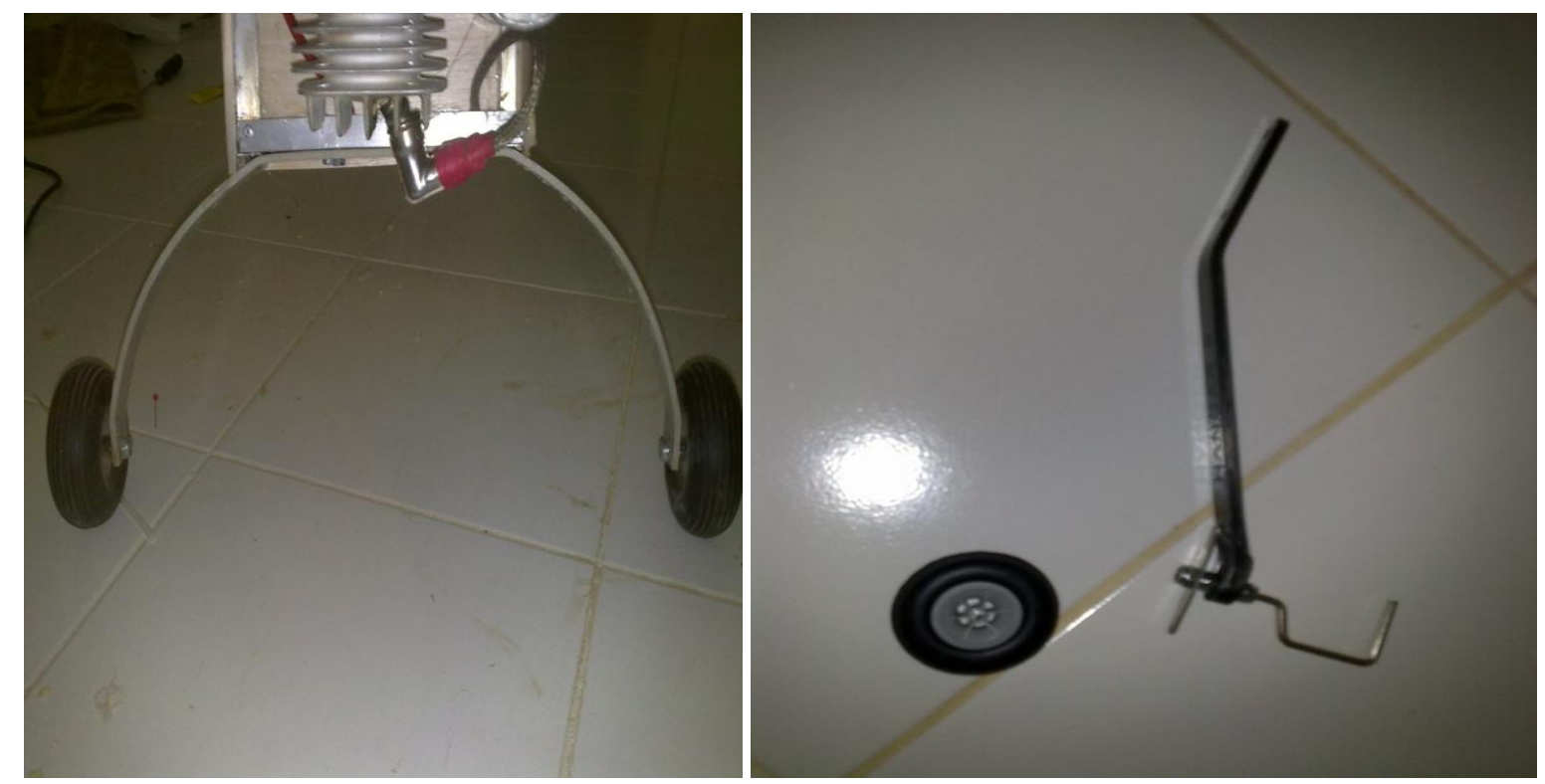

Fig. 13 The landing gears of the ASUAV 


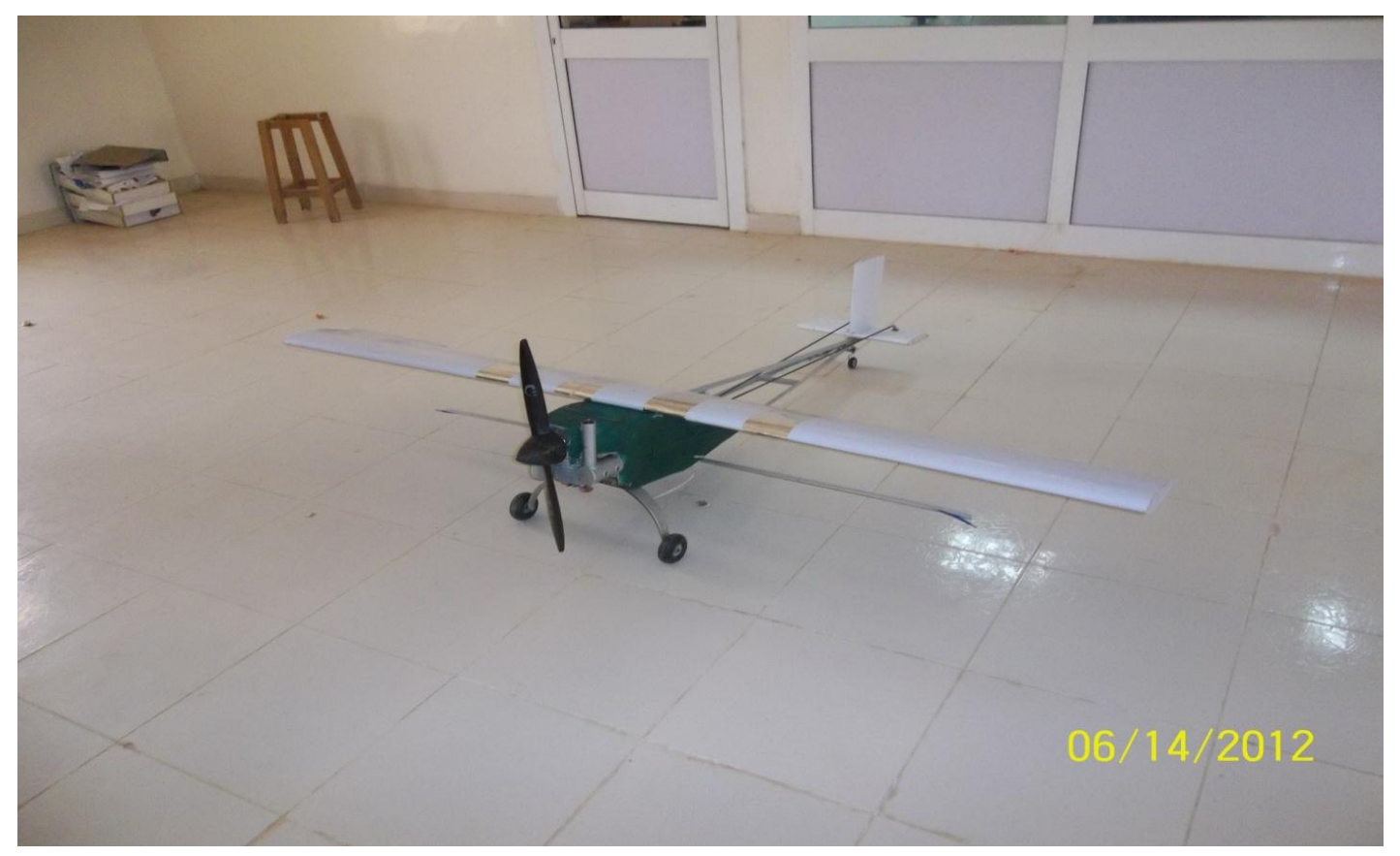

Fig. 14 The final scaled model of the ASUAV

\section{Flight Test}

The electrical system is installed in the ASUAV model, which is tested on ground for its response to signals. Futaba radio transmitter is used for this test. Engine is started and warmed up.

The ASUAV model flew successfully on the sixteenth of June 2012 for ten minutes. Figure 15 shows the ASUAV model during its fly test.

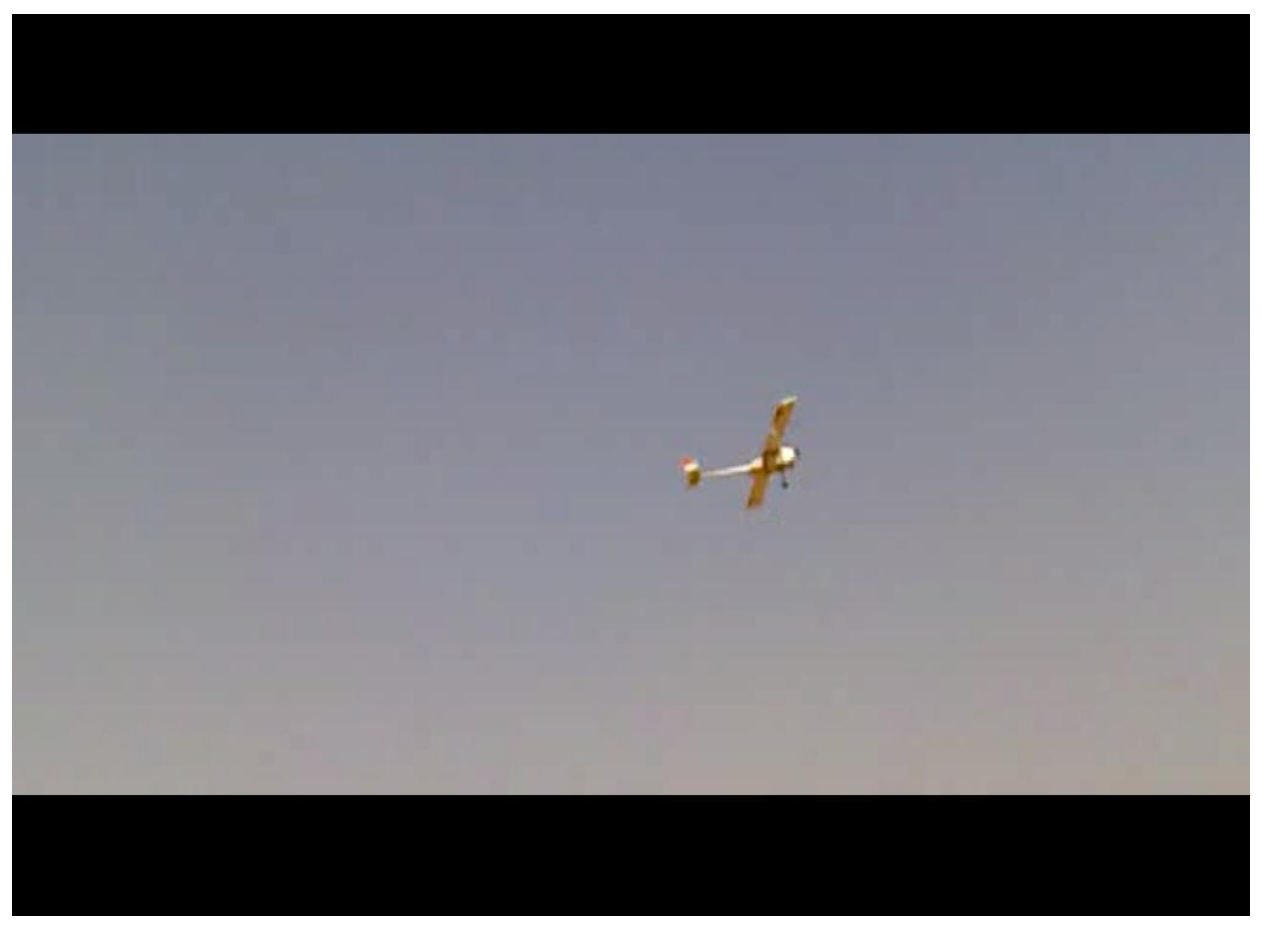

Fig. 15 The ASUAV during the flight test 


\section{Conclusion}

The present work has used CFD techniques to perform an aerodynamic evaluation of an ASUAV configuration. The results obtained seem to corroborate many of the historical reports. A geometrically simplified model of the ASUAV is fabricated to achieve the designed mission requirements and the developed design and manufacturing process proved to be efficient for small ASUAV from point of view of labor and cost.

\section{References}

[1] H. K. Versteeg and W. Malalasekera, An introduction to computational fluid dynamicsThe finite volume method, Longman Group Ltd copyright 1995.

[2] Dr. Jan Roskom, Airplane Design, Roskom Aviation and Engineering Corporation, 1985.

[3] John David Anderson, Introduction to Flight, McGrow-Hill/ 2006.

[4] Daniel P. Raymer, Aircraft Design, American Institute of Aeronautics and Astronautics, Inc., 2002.

[5] Baudu N. Pamadi, Performance, Stability, Dynamics, and control of airplanes, American Institute of Aeronautics and Astronautics, Inc., Reston / 2001. 